\title{
PLANT-PEST-NATURAL ENEMY MODEL WITH IMPULSIVE BIOLOGICAL AND CHEMICAL CONTROL
}

\author{
Vandana Kumari, Sudipa Chauhan, Sumit Kaur Bhatia \\ AND JOYDIP DHAR
}

\begin{abstract}
In this paper, a plant pest mathematical model is presented with integrated pest management through impulse. Two control measures: Biological(Natural Enemies) and Chemical pesticides are taken in consideration in the model through impulse. Boundedness and the sufficient conditions of existence of the positive periodic solutions is established. Further, the local stability of the pest extinction equilibrium point is studied using Floquet's theory. It is proved that the pest extinction equilibrium point is globally stable at $T<T_{\max }$ and the system is permanent for $T>T_{\max }$. Numerical data per week are taken to illustrate the theoretical results using MATLAB software.
\end{abstract}

Mathematics subject classification (2010): 34A37, 92D25.

Keywords and phrases: Plant-Pest-natural enemy, boundedness, local stability, impulse, periodic solution, permanence.

\section{REFERENCES}

[1] L. Holmes, S. Mandjiny, And D. Upadhyay, Biological Control of Agriculture Insect Pests, European Scientific Journal May, 2016, 1857-1887.

[2] M. A Kishimba, L. Henry, H. Mwevura, A. J Mmochi, M. Mihale and H. Hellar, The status of pesticide pollution in Tanzania, National Bureau of Standards, Applied Mathematics Series $641,2014,48-53$.

[3] D. G JAMES, Imidacloprid increases egg production in Amblyseius victoriensis, Experimental. and Applied. Acarology 21, 1997, 75-82.

[4] DR. David, G. JAmes, TANYA And S. PRICE, Imidacloprid Boosts TSSM Egg Production, Agriculture and environmental news 189, 2002, 1-11.

[5] L. Bing, X. Ling, K. Baolin And L. Bin, Dynamics of a Stage Structured Pest Control Model in a Polluted Environment with Pulse Pollution Input, Journal of Applied Mathematics 8, 2013.

[6] A. Wilby, M. B. Thomas, Natural enemy diversity and pest control: patterns of pest emergence with agricultural intensification, Ecology Letters 5, 2002, 353-360.

[7] Y. Zhang, B. LIU AND L. CHEN, Dynamical behaviour of Volterra model with mutual interference concerning IPM, Mathematical Modelling and Numerical Analysis 38, 2004, 143-155.

[8] Y. Song, X. Wang And W. JiAng, he Pest Management Model with Impulsive Control, Applied Mechanics and Materials, 2014, 1299-1304.

[9] L. Changguo, P. Yongzhen and J. Xuenui, Dynamic Behavior of a Multiple Species PreyPredator System with Impulsive Chemical and Biological Control, Natural Computation 5, 2009, 477 481.

[10] K. S. JATAVA AND J. DHAR, Hybrid Approach for Pest Control with impulsive releasing of natural enemies and chemical pesticides:A plant-pest-natural enemy model, Nonlinear Analysis Hybrid Systems 12, 2014, 79-92.

[11] P. J. WANGERS Ky AND W. J. Cunningham, Time lag in prey-predator population models, Ecology 38, 1957, 136-139.

[12] P. CulL, Global stability of population model, Bulletin of mathematical Biology, 43, 1, (1981), 47-58. 
[13] D. D. BAINov AND P. S. Simeonov, Impulsive Differential Equations:Periodic solutions and applications, Pitman Monographs and Surveys in Pure and Applied Mathematics, 1993, 66.

[14] V. Lakshmikantham, D. Bainov, P. Simeonov, Theory of Impulsive Differential Equations, World Scientific Publisher, Singapore, 1989, 288. 